\title{
Sterility Assurance of Parenteral Products - Major Deficiency for Recall
}

Lakshmi Prasanna Kolluru*

Medefil Inc., Glendale Heights, IL 60139, USA

*Corresponding author: Lakshmi Prasanna Kolluru, Sr. Formulation Scientist, Medefil Inc., 250/405 Windy Point Drive, Glendale Heights, IL 60139, USA, Tel: +1-612-865-7725; E-mail: lakshmi.prasanna.kolluru@gmail.com

Received date: March 13, 2017; Accepted date: March 17, 2017; Published date: March 24, 2017

Copyright: (c) 2017 Kolluru LP. This is an open-access article distributed under the terms of the Creative Commons Attribution License, which permits unrestricted use, distribution, and reproduction in any medium, provided the original author and source are credited.

\section{Editorial}

Sterility is one of the most important Critical Quality Attribute (CQA) for all parenteral drug products as they are intended to circumvent body's defense mechanisms and rapidly enter blood circulation. When the sterility of such products is compromised, it leads to microbial contamination of the drug product and/ or presence of particles leading to serious adverse events including death.

Lack of sterility assurance is a leading contributor to safety alerts and product recalls by Food and Drug Administration (FDA). Table 1

\begin{tabular}{|c|c|c|}
\hline Drug Product & Manufacturer & Reason for Recall \\
\hline $5 \%$ Dextrose Injection USP in PAB Container & B. Braun Medical Inc. & Leakage and/or Particulate Matter \\
\hline Eye Wash/Eye Irrigating Solutions & United Exchange Corp & Microbial Contamination \\
\hline Eye Saline Eye Wash & Honeywell & Microbial Contamination \\
\hline Lyophilized HCG and Sermorelin & Talon Compounding Pharmacy & Lack of Sterility Assurance \\
\hline Human and Animal Sterile Drug Products & I.V Speciality Ltd & Lack of Sterility Assurance \\
\hline Sterile Drug Products & Cantrell Drug Company & Lack of Sterility Assurance \\
\hline Sterile Drug Products & Medaus Pharmacy & Lack of Sterility Assurance \\
\hline Sterile Drug Products & Pharmakon Pharmaceuticals & Lack of Sterility Assurance \\
\hline Sterile Drug Products & Tri-coast Pharmacy & Lack of Sterility Assurance \\
\hline Sterile Human and Animal Compounded Products & Abbott Compounding Pharmacy & Lack of Sterility Assurance \\
\hline Sterile Compounded Products & Well Care Compounding Pharmacy & Lack of Sterility Assurance \\
\hline Sterile Products & Wells Pharmacy Network & Lack of Sterility Assurance \\
\hline
\end{tabular}

Table 1: FDA safety alerts for drugs and biological products with compromised sterility in 2016.

Correction of sterility related deficiencies is usually time consuming and as it involves a team of facility engineers, manufacturing personnel, validation engineers and product development scientists to come together and fix the root cause of the problem. Hence, maintaining sterility of parenteral drug products throughout the product lifecycle and prevention of sterility related deficiencies is of utmost importance. Administrative bodies including FDA [6,7] and International Conference on Harmonization (ICH) [8,9] have developed set of guidance's and reference procedures to be followed for successfully developing and testing a finished product with sterility assurance.

Various methods of sterilization including moist heat sterilization, dry heat sterilization, ethylene oxide sterilization or sterilization by aseptic filtration are available and a mode of sterilization is selected based on product specifications. As a general rule of thumb, terminal summarizes the safety alerts to parenteral products and drug manufacturers in 2016 [1]. Lack of sterility assurance can be product specific (probably caused by container closure integrity leakage) or manufacturing site specific (caused by poor facility and engineering or improper manufacturing practices) affecting all the drug products manufactured in the affected site. Such instances lead to major deficiencies during FDA facility inspections sometimes even leading to ceasing of all manufacturing operations until rectified [1-5]. sterilization is the most preferred method of sterilization unless the container/closure system or drug product is not deemed to be suitable for terminal sterilization procedures $[10,11]$.

Sterility of a finished product is assessed by monitoring microbial growth or turbidity as per USP $<71>$ at product release and annually on stability throughout product shelf life [2]. Additionally, Bacterial Endotoxin Test (BET) is evaluated for all parenteral products as per USP <81> to monitor bio burden of the drug product [3]. Furthermore, Container Closure Integrity Testing (CCIT) is also evaluated on all drug products at release and on stability to ensure sterility of the drug products $[4,5]$. In addition to ensuring product sterility, care has to be taken to ensure appropriate environmental and engineering controls at the manufacturing site to develop a product with acceptable sterility assurance [6]. 
Citation: Lakshmi Prasanna K (2017) Sterility Assurance of Parenteral Products-Major Deficiency for Recall. J Pharmacovigil 5: e168. doi:

Page 2 of 2

In conclusion, maintaining sterility of drug products intended for parenteral administration is of utmost importance and current good manufacturing practices to ensure sterility assurance has to be followed throughout product lifecycle.

\section{References}

1. Food and Drug Administration (FDA) (2016) Safety Alerts for Human Medical Products.

2. http://www.pharmacopeia.cn/v29240/usp29nf24s0_c71.html

3. http://www.pharmacopeia.cn/v29240/usp29nf24s0_c85.html

4. http://pdamidwest.org/images/presentations/NovemberLi.pdf

5. Guidance for Industry (2008) Container and Closure System Integrity Testing in Lieu of Sterility Testing as a Component of Stability Protocol for Sterile Products. FDA.
6. Guidance for Industry (2004) Sterile Drug Products Produced by Aseptic Processing-Current Good Manufacturing Practices. FDA.

7. Guidance for Industry (2003) Sterile Drug Products Produced by Aseptic Processing-Current Good Manufacturing Practices. FDA.

8. ICH Harmonized Tripartite Guideline (1999) Specifications: Test Procedures and Acceptance Criteria for New Drug Substances and New Drug Products: Chemical Substances.

9. ICH Harmonized Tripartite Guideline (2010) Evaluation and Recommendation of Pharmacopoeial Texts for Use in the ICH Regions on Sterility Test.

10. Siew A (2013) Ensuring Sterility of Parenteral Products. Pharma Tech.

11. https://www.fda.gov/downloads/ICECI/ComplianceManuals/ ComplianceProgramManual/UCM125409.pdf 